\title{
Diet Diversity and Dietary Overlap of Two Sympatric Vulture Species in Hirpora Wildlife Sanctuary, Kashmir
}

\author{
Mustahson F. Fazili ${ }^{1}$, Hameem Mushtaq Wani ${ }^{1 *}$, Samina A. Charoo ${ }^{2}$ and Umer Hameed Shansaz ${ }^{1}$ \\ ${ }^{1}$ Department of Zoology, University of Kashmir, Srinagar-190006, India \\ ${ }^{2}$ Department of Wildlife protection, Government of J\&K, Srinagar-190006, India \\ *Corresponding author: hameem.scholar@kashmiruniversity.net
}

\begin{abstract}
Article History: 20-218 Received: 11-Oct-2020 Revised: 03-Dec-2020 $\quad$ Accepted: 05-Dec-2020
ABSTRACT

Bird species that use similar resources are expected to use variant foraging approaches and segregate in order to minimize a possible competition among them. However, if they fail to attain this exclusion, competition results. We studied the diet composition and dietary overlap between two sympatric vulture species: Himalayan vulture (Gyps himalayensis) and Bearded vulture (Gypaetus barbatus), the two important avian scavengers of Hirpora Wildlife Sanctuary of Kashmir Himalaya. Analysis of pellets collected from feeding and roosting sites of these vulture species revealed a significant variation in their food consumption with Himalayan species consuming mostly larger dead mammalian species with higher frequency occurrence of $66.66 \%$ of Bubalus bubalus and bearded species the smaller dead mammalian ones with highest frequency occurrence of Ovis aries (83.82\%). Diet spectrum of Himalayan vulture was more diverse $\left(\mathrm{H}^{\prime}=1.97\right)$ than that of Bearded vulture $\left(\mathrm{H}^{\prime}=1.64\right)$. The values of Berger-Parker index $\left(\mathrm{P}_{\text {imax }}\right)$ follows the reverse order of diversity with $\mathrm{P}_{\max }=36.2 \%$ for Himalayan vulture and $\mathrm{P}_{\mathrm{imax}}=48.7 \%$ for Bearded vulture. There was very low dietary overlap between the two species $\left(\mathrm{O}_{j k}=0.466 ; \mathrm{C}=0.457\right)$ which may favor their co-existence. The management of carrions of livestock and setting up of vulture restaurants is the need of the hour for the conservation of these scavenging birds which are facing high risk of extinction in Hirpora Wildlife Sanctuary.
\end{abstract}

Key words: Diet, vultures, Hirpora, Shopian, Kashmir.

\section{INTRODUCTION}

To understand the tropic relationships in animal communities, the assessment of information on the use of food resources is of utmost importance (Pianka 1974; Bianchi 2009). When such information is available, generalizations can be made about various ecological aspects such as foraging strategies and adaptations to various habitats of organisms (Pianka 1975). When resource requirements are similar, competition between sympatric species occurs throughout the annual cycle; however, this competition is reduced by niche differentiation that allows resource partitioning and promotes co-existence (Sabo 1980; Schmutz et al. 1980; Reynolds and Meslow 1984; Golawski et al. 2020). Moreover, knowledge of diet composition and dietary preferences have key influences in the conservation of threatened faunal elements (González et al. 2006) and increase population distribution (Jones 2004). Further, observed dietary preferences are likely to be restricted because of optimum prey-species availability (Hayward et al. 2006) and these species are likely to be of considerable significance to conservation programs. Thus, a comprehensive knowledge of dietary preferences helps us to identify the obstacles before conservation programs permitting concerned shareholders to enhance their rate of success.

An important challenge before birds is to discover and utilize food resources. For this purpose, they must keep stability and equilibrium between the amounts of energy that is spent to the amount of energy that is gained (Pianka 1985; Gutiérrez 1998). An important mechanism that animals use to decrease the competition cost is to occupy different niches. So, by utilizing various methods to reduce competition, they distinguish in what, where and when to eat. If these ways and means overlap, competition may result and that is detrimental to both the species and can spark extinction in due course of time (Pianka 1985).

Generally, scavengers have not been taken into account in food web studies (Wilson and Wolkovich 2011). The availability of carrion can vary spatially and seasonally, thereby, playing an important part in movement and distribution of species feeding on it and stabilizing food

Cite This Article as: Fazili MF, Wani HM, Charoo SA and Shansaz UH, 2021. Diet diversity and dietary overlap of two sympatric vulture species in Hirpora Wildlife Sanctuary, Kashmir. International Journal of Veterinary Science 10(3): 185190. https://doi.org/10.47278/journal.ijvs/2021.049 
chains and food webs (Wilson and Wolkovich 2011; Barton et al. 2013). Solid coexistence of different species on same carrion is plausible if there is resource portioning, allowing various species to get segregated in space and time. Therefore, the intervening species need to adapt behaviorally and anatomically to reduce niche overlap and maintain coexistence equilibrium (Houston 1988; MorenoOpo et al. 2016). Competition allows more aggressive partners to monopolise resources and displace the competition when there is scarcity of resources (Hiraldo et al. 1991; Stolen 1996).

In Hirpora WLS, carrion is utilized by various scavenging animal groups. The principal aerial scavengers are represented by family Accipitridae (Order: Accipitriformes): the Himalayan vulture (Gyps himalayensis) (Wani et al. 2020a) and Bearded vulture (Gypaetus barbatus); and family Corvidae (Order: Passeriformes): Common raven (Corvus corax) (Pers. Obs.). Therefore, there could be competition at least among obligate scavengers for ephemeral carrion (Ballejo et al. 2017).

Vultures occupy a vital position in an ecosystem as efficient scavengers (Kichloo et al. 2020). The Himalayan vulture feeds on old carcasses and typically eat only fleshy parts (Rasmussen and Anderton 2005), whereas bearded vulture usually disdains the actual meat and take bone marrow (Hiraldo et al. 1979; Brown 1988; Wani et al. 2018). However, comparative studies on dietary overlap of Himalayan vulture and Bearded vulture are lacking. Therefore, our motive behind this study was to determine the diet composition of these two scavenging bird species from Hirpora WLS via pellet analysis. We expect a less overlap between the two vulture species that will facilitate their coexistence.

\section{MATERIALS AND METHODS}

\section{Study Area}

Hirpora Wildlife Sanctuary (3339' $55^{\prime \prime}$ 'N latitude and 74'39'40' E longitude), located in Kashmir Division of Jammu and Kashmir at 2546 m.a.s.l. and spreads over an area of about $341 \mathrm{~km}^{2}$. About $78 \%$ of the area is rocky (Rather 2016). The area is known for its rich floral and faunal diversity. The vegetation is divided into subalpine pastures, deciduous subalpine scrub forest and mixed coniferous forests (Ahmad et al. 2011; Ahmad et al. 2015). The main faunal elements include- Capra falconeri, Moschus leucogaster, Vulpes vulpes, Gyps himalayensis and Gypaetus barbatus (Wani et al. 2020b).

\section{Pellet Collection}

During field observations, the fecal pellets of Himalayan vulture and Bearded vulture were collected (in $50 \mathrm{ml}$ collection tubes) whenever available from feeding grounds and from their roosting places (Fig 1). However, we could not collect any fecal sample from December to February because the sanctuary remained under heavy snow cover during these months that prevented us from reaching to appropriate roosting sites for sample collection. So, we were not enable to analyze our data on seasonal basis.

\section{Pellet Analysis}

For the purpose of cuticular examination, hair samples were extracted from each collected pellet. $15 \mathrm{~g}$ of gelatin were added to $100 \mathrm{ml}$ of water to prepare a gelatin solution of $10-20 \%$. In order to fully dissolve the gelatin granules, the whole mixture was stirred constantly while heating at about $60^{\circ} \mathrm{C}$. A thin film of gelatin was prepared on the slide. Strands of hair were placed side by side on the slide using a pair of tweezers. The hairs were left overnight and then they were removed from the set gel the following morning. The imprints of the cuticular scales in the gel cast were examined under a light microscope (Cornally and Lawton 2016) and collated with reference slides and other reference keys (Faliu et al. 1980; Chehébar and Martín 1989; Teerink 1991).

\section{Data Analysis}

We expressed our results on diet composition as percentage of frequency $(\mathrm{F} \%)$ and percentage of occurrence $(\mathrm{O} \%)$ which correspond to number of times each item is encountered with respect to overall number of food items in all pellets and occurrence of each item with respect to overall number of pellets respectively. Dietary diversity was measured by Shannon index (H') dietary overlap was computed by using Pianka's index $\left(\mathrm{O}_{j k}\right)$ (Pianka 1973), Morisita-Horn index (C) and Percentage overlap. Pianka's index varies between 0 (complete separation) and 1 (complete overlap); values greater than 0.60 depict the overlap (Orlowski and Karg 2013). Similarly, we used Berger-Parker index $\left(\mathrm{P}_{\text {imax }}\right)$ to measure the dominance of one prey category in diet (Magurran 1988). To determine whether there is any significant difference in the diet selection of two vulture species we applied the $\mathrm{X}^{2}$-test.

\section{RESULTS}

A total of 316 food items from 176 fecal pellets of vultures (Himalayan vulture $(n=108)$, Bearded vulture $(n=68)$ ) that were collected from Hirpora Wildlife sanctuary were isolated and analyzed. From a total of 316 food items, $62.97 \%$ belonged to Himalayan vulture $(n=199)$ whereas $37.03 \%$ belonged to Bearded vulture $(n=117) . X^{2}$-test showed that there is a significant variation $\left(\mathrm{X}^{2}=91.98 ; \mathrm{df}=11 ; \mathrm{P}=000\right)$ in the consumption of food between Himalayan and Bearded vulture.

\section{Diet Composition}

Among 199 food items that were identified from 108 pellet samples of Himalayan vulture, most of them belonged to Bubalus bubalus $(\mathrm{n}=72)$, followed by Equus ferus $(\mathrm{n}=30)$, Capra aegagrus $(\mathrm{n}=27)$, Ovis aries $(\mathrm{n}=25)$ and others (Table 1). Consequently, the percentage frequency $(\% \mathrm{~F})$ and percentage occurrence $(\% \mathrm{O})$ were highest for Bubalus bubalus $(\% \mathrm{~F}=36.18$ and $\% \mathrm{O}=66.66)$, followed by Equus ferus $(\% \mathrm{~F}=15.07$ and $\% \mathrm{O}=27.80)$, Capra aegagrus $(\% \mathrm{~F}=13.57$ and $\% \mathrm{O}=25.00)$, Ovis aries $(\% \mathrm{~F}=12.57$ and $\% \mathrm{O}=23.14)$ and others (Table 1). Overall, there were $83.41 \%$ domestic species viz. Sheep (Ovis aries), Goat (Capra aegagrus), Cow (Bos taurus), Buffalo (Bubalus bubalus), Dog (Canis familaris) and Horse (Equus ferus) present in the diet of Himalayan vulture (Gyps himalayensis) in which $51.25 \%$ alone composed of Buffalo (Bubalus bubalus) and Horse (Equus ferus) in Hirpora Wildlife Sanctuary. 
Table 1: Diet composition of Himalayan vulture (Gyps himalayensis) in Hirpora Wildlife Sanctuary, Kashmir. We present the number of food items (n), Frequency percentage $(\% \mathrm{~F})$ corresponding to the percentage of the total number of food items

\begin{tabular}{llcc} 
& & \multicolumn{2}{c}{ Himalayan vulture } \\
\cline { 2 - 4 } S. No. & Food category & $\mathrm{N}$ & $\% \mathrm{~F}$ \\
\hline 1 & Sheep (Ovis aries) & 25 & 12.56 \\
2 & Goat (Capra aegagrus) & 27 & 13.57 \\
3 & Cow (Bos taurus) & 12 & 6.03 \\
4 & Buffalo (Bubalus bubalus) & 72 & 36.18 \\
5 & Dog (Canis familaris) & 5 & 2.51 \\
6 & Horse (Equus ferus) & 30 & 15.07 \\
7 & Markhor (Capra falconeri) & 3 & 1.50 \\
8 & Musk deer (Moschus leucogaster) & 7 & 3.52 \\
9 & Black bear (Ursus thibetanus) & 0 & 0.00 \\
10 & Brown bear(Ursus arctos) & 0 & 0.00 \\
11 & Leopard (Panthera pardus) & 0 & 0.00 \\
12 & Cat (Felis catus) & 3 & 1.50 \\
13 & Red fox (Vulpes vulpes) & 5 & 2.51 \\
14 & Tibetan Wolf (Canis lupus) & 4 & 2.01 \\
15 & Others $\quad 6$ & 3.01 \\
& $\quad$ Total no. food items & \multicolumn{2}{c}{199} \\
& $\quad$ Total no. of pellets & \multicolumn{2}{c}{108} \\
\hline
\end{tabular}

Table 2: Diet composition of Bearded vulture (Gypaetus barbatus) in Hirpora Wildlife Sanctuary, Kashmir. We present the number of food items (n), Frequency percentage $(\% \mathrm{~F})$ corresponding to the percentage of the total number of food items

\begin{tabular}{llcc}
\hline & & \multicolumn{2}{c}{ Bearded vulture } \\
\cline { 3 - 4 } S. No. & \multicolumn{1}{c}{ Food category } & $\mathrm{N}$ & $\% \mathrm{~F}$ \\
\hline 1 & Sheep (Ovis aries) & 57 & 48.71 \\
2 & Goat (Capra aegagrus) & 25 & 21.36 \\
3 & Cow (Bos taurus) & 4 & 3.42 \\
4 & Buffalo (Bubalus bubalus) & 2 & 1.70 \\
5 & Dog (Canis familaris) & 4 & 3.42 \\
6 & Horse (Equus ferus) & 7 & 5.98 \\
7 & Markhor (Capra falconeri) & 0 & 0.00 \\
8 & Musk deer (Moschus leucogaster) & 5 & 4.27 \\
9 & Black bear (Ursus thibetanus) & 0 & 0.00 \\
10 & Brown bear (Ursus arctos) & 0 & 0.00 \\
11 & Leopard (Panthera pardus) & 0 & 0.00 \\
12 & Cat (Felis catus) & 6 & 5.12 \\
13 & Red fox (Vulpes vulpes) & 0 & 0.00 \\
14 & Tibetan Wolf (Canis lupus) & 3 & 2.56 \\
15 & Others & 4 & 3.42 \\
& Total no. of food items & \multicolumn{2}{c}{117} \\
& $\quad$ Total no. of pellets & \multicolumn{2}{c}{68} \\
\hline
\end{tabular}

Table 3: Various statistical parameters pertaining to the diet composition and dietary overlap between Himalayan vulture (Gyps himalayensis) and Bearded vulture (Gypaetus barbatus) in Hirpora Wildlife Sanctuary, Kashmir

Statistical parameter Himalayan vulture Bearded vulture

\begin{tabular}{|c|c|c|}
\hline Shannon index(H') & 1.97 & 1.64 \\
\hline Berger-Parker index $\left(\mathrm{P}_{\text {imax }}\right)$ & $36.2 \%$ & $48.7 \%$ \\
\hline Pianka's index $\left(\mathrm{O}_{j k}\right)$ & \multicolumn{2}{|c|}{0.466} \\
\hline Morisita-Horn index (C) & \multicolumn{2}{|c|}{0.457} \\
\hline Percentage overlap & \multicolumn{2}{|c|}{$49.80 \%$} \\
\hline $\mathrm{X}^{2}$-test & $X^{2}=91$ & $\mathrm{P}=000$ \\
\hline
\end{tabular}

Likewise, among 117 food items that were isolated and identified from 68 pellet samples of Bearded vulture, most belonged to Ovis aries $(\mathrm{n}=57)$, followed by Capra aegagrus $(n=25)$ and others (Table 2). Consequently, the Frequency percentage $(\% \mathrm{~F})$ and percentage occurrence $(\% \mathrm{O})$ were highest for Ovis aries $(\% \mathrm{~F}=48.71$ and $\% \mathrm{O}=83.82)$, followed by Capra aegagrus $(\% \mathrm{~F}=21.36$ and $\% \mathrm{O}=36.76)$, and others (Table 2 and Fig.3). Overall, 70.07\% diet of Bearded vulture comprised of sheep and goat only.

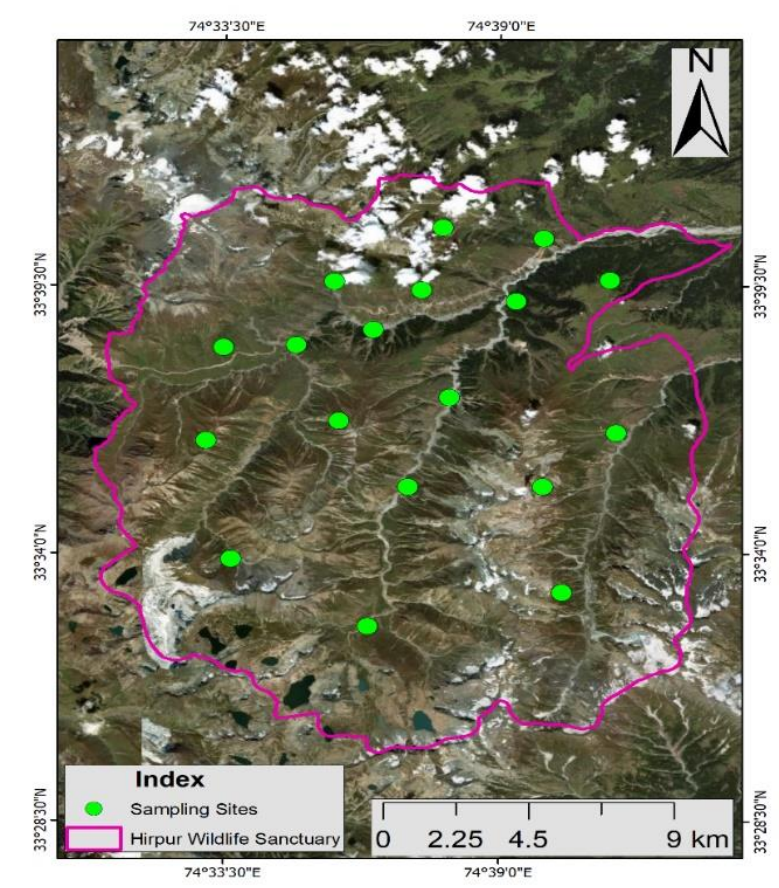

Fig. 1: Map of Hirpora Wildlife Sanctuary showing some important sampling sites.

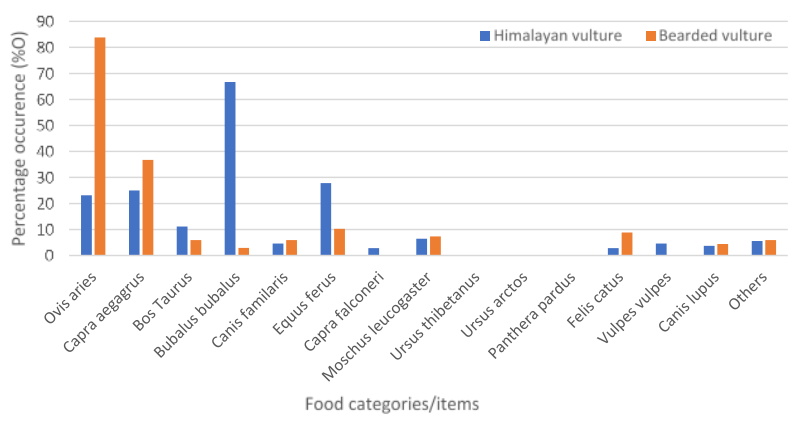

Fig. 2: Percentage occurrence of different food items in the diet spectrum of Himalayan vulture and Bearde vulture.

\section{Diet Diversity and Dietary Overlap}

Diet spectrum of Himalayan vulture (Gyps himalayensis $)\left(\mathrm{H}^{\prime}=1.97\right)$ was more diverse than that Bearded vulture (Gypaetus barbatus) $\left(\mathrm{H}^{\prime}=1.64\right)$. However, prey dominance (Berger-Parker index) followed the inverse order of diversity (Table 3 ), with Bearded vulture (Gypaetus barbatus) having the lower diversity and higher dominance and Himalayan vulture (Gyps himalayensis) having the higher diversity and lower dominance. Piankas's index showed that there is very low dietary overlap $\left(\mathrm{O}_{j k}=0.466 ; \mathrm{C}=0.457\right)$ between the two vulture species which was also confirmed and authenticated by Morisita-Horn index $(\mathrm{C}=0.457)$ (Table 3). The diet spectrum of Himalayan vulture (Gyps himalayensis) was dominated by Bubalus bubalus $\left(\mathrm{P}_{\text {imax }}=36.18\right.$ ) whereas that of Bearded vulture (Gypaetus barbatus) by Ovis aries $\left(\mathrm{P}_{\text {imax }}=48.71\right)$ (Table 3).

\section{DISCUSSION}

\section{Diet Composition}

Diet and food intake is a crucial component of animal ecology; therefore, their knowledge is key to the 
understanding of occurrence patterns, habitat utilization and breeding success of a species (Donázar and Ceballos 1988; Litvaitis 2000; Sonerud et al. 2002; Sarà and Divittorio 2003; Zduniak and Kuczynski 2003; Pande et al. 2018). Several studies on the decline of vultures have been done (Kanaujia et al. 2013) but studies on their dietary habits and dietary overlap which are of paramount importance for the mutual and long-term survival of the sympatric species and deciphering of higher level of trophic relationships in an ecosystem (Taher et al. 2016), are limited. This study regarding the diet composition and dietary overlap of Gyps himalayensis and Gypaetus barbatus being first of its kind will set the foundation for the detailed study on various ecological parameters of these sympatric scavenging bird species. Himalayan vulture (Gyps himalayensis) feeds exclusively on carrion (Brown and Amadon 1986) and its diet is composed of both domestic yak (Bos grunniens) as well as wild ungulates such as Equus kiang and Pantholops hodgsonii (Li and Kasorndorkbua 2008; Lu et al. 2009; Virani et al. 2008). During present study the consumption of both wild as well as domestic ungulates was also observed in diet spectrum of Himalayan vulture (Gyps himalayensis). On Tibetan Plateau their diet is composed of about $61 \%$ of dead domestic yak (Bos grunniens) elucidating the importance of domestic livestock in the survival of Himalayan vulture. Our results revealed the presence of $83.41 \%$ of domestic species viz. Sheep (Ovis aries), Goat (Capra aegagrus), Cow (Bos taurus), Buffalo (Bubalus bubalus), Dog (Canis familaris) and Horse (Equus ferus) in the diet of Himalayan vulture (Gyps himalayensis) in Hirpora Wildlife Sanctuary and $51.25 \%$ of which is composed of Buffalo (Bubalus bubalus) and Horse (Equus ferus). The management of large sized mammals in the area is therefore, essential for the conservation of Himalayan vulture. Diet of Bearded vulture is also dominated by domestic livestock as $81.17 \%$ was composed of it. These findings are similar to that of Southern African study which has reported that domestic livestock forms over $80 \%$ of its diet (Brown and Plug 1990). Margalida et al. (2009), found that bearded vulture avoids the remains of larger species and prefers small sized species as $60 \%$ of its diet is composed of sheep and goat. Hence, it did not select prey items with respect to their availability. Such selection can be collated with cost-tobenefit ratio, that is, the energy and time spend in handling, its nutrient content and ingestion of larger bones (Margalida 2008). During current study, 70.07\% diet of Bearded vulture comprised of sheep and goat, as the weight and size of their bone remains can be handled and transported easily by the bearded vulture. Hence, management of such medium-sized ungulates (both wild as well as domestic) in Hirpora Wildlife Sanctuary may be deemed as the most important consideration for conservation of Gypaetus barbatus.

\section{Diet Diversity and Dietary Overlap}

In order to retain a demographic balance among various populations of a community, species have specific feeding strategies and inhabit defined tropic niches. If a species moves apart from this balance, increase in niche overlap may take place, which results in competition for different resources (Pianka 1985). The diet of Himalayan vulture (Gyps himalayensis) was diverse than Bearded vulture (Gypaetus barbatus). The former feeds on almost all parts of the carcass while later prefers limbs, pieces of muscles, tendon, mid-sized viscera, mixed scraps of meat and small bones mainly from those parts with high nutritive content (Kanaujia et al. 2019). The Old-World vultures are spatially and temporally separated in use of food resources (Kruuk 1967; Blázquez et al. 2009; Cortés-Avizanda 2010; Kendall et al. 2012; Moreno-Opo et al. 2016). Various overlap indices like Pianka's index and Morisita-Horn index calculated during current study have shown very low overlap in the diet composition of Himalayan vulture (Gyps himalayensis) and Bearded vulture (Gypaetus barbatus). Also, there being apparent morphological and physiological adaptations between the two vulture species that help them in exploitation of different parts of a carrion (Margalida 2008; Kanaujia and Kushwaha 2013) with no interdependence and far less competition between the two that facilitates coexistence in them.

\section{Conclusion}

Management of carrion furnished by animals that die due to traffic on historic Mughal road or that die naturally in Hirpora Wildlife Sanctuary is an important conservation tool for scavenging birds in general and Himalayan and Bearded vultures in particular in the area. Setting up of supplementary feeding stations or vulture restaurants in Hirpora Wildlife Sanctuary may help breeding vulture populations to overcome harsh winter months when the sanctuary remains snow covered.

\section{Acknowledgements}

We are highly thankful to the department of Zoology, University of Kashmir for providing necessary equipment to carry out this work. Thanks, are also due to the Department of Wildlife protection, J\&K for providing us the permission for data collection in the field. We are grateful to Mr. Bashir A. Bhat (Ex-Field assistant WTI), Mr. Shabir A. Bhat (Field assistant WTI) and Late Mr. Md. Akbar War (Ex-Field assistant WTI) who helped us during data collection in Hirpora Wildlife Sanctuary.

\section{Author's Contribution}

HMW collected and analysed the data and prepared the manuscript. UHS prepared the map showing sampling points. MFF and SAC reviewed and approved the final version of the manuscript.

\section{Conflict of Interests}

The authors declare that they have no conflicting interests.

\section{REFERENCES}

Ahmad F, Hassan Z, Farooq S and Shah JA, 2015. Assessment of Land Use/ Land Cover Change in Hirpora Wildlife Sanctuary, Kashmir. Asian Journal of Earth Science 8: 6473. https://doi.org/10.3923/ajes.2015.64.73

Ahmad R, Haq S, Querishi S, Puri M and Kaul R, 2011. The lost Markhor of Pirpinjal; Assessing the distribution of markhor (Capra falconeri) and other important fauna along with southern slopes of Pirpanjal with special reference to resource competition with local grazier communities, in Hirpora WLS, Jammu and Kashmir. Wildlife Trust of India, Delhi. 
Ballejo F, Lambertucci SA, Trejo A and De Santis LJM, 2017. Trophic niche overlap among scavengers in Patagonia supports the condor-vulture competition hypothesis. Bird Conservation International 28: 390-402. https://doi.org/ 10.1017/S0959270917000211

Barton PS, Cunningham SA, Lindenmayer DB and Manning AD, 2013. The role of carrion in maintaining biodiversity and ecological processes in terrestrial ecosystems. Oecologia 171: 761-772. https://doi.org/10.1007/s00442-012-2460-3

Bianchi RC 2009. Ecologia de mesocarnívorosemumaárea no Pantanal Central, MatoGrosso do Sul. Tese de Doutorado. Centro de CiênciasBiológicas e da Saúde, Universidade Federal de Mato Grosso do Sul, Campo Grande, M.S. 193p.

Blázquez M, Sánchez-Zapata JA, Botella F, Carrete M and Eguía S, 2009. Spatiotemporal segregation of facultative avian scavengers at ungulate carcasses. Acta Oecologica 35: 645650. https://doi.org/10.1016/j.actao.2009.06.002

Brown CJ and Plug I, 1990. Food choice and diet of the Bearded Vulture Gypaetus barbatus in southern Africa. South African Journal of Zoology 25: 169-177. https://doi.org/ 10.1080/02541858.1990.11448207

Brown CJ, 1988. A study of the Bearded Vulture Gypaetus barbatus in southern Africa. Ph.D. Thesis, University of Natal, Pietermaritzburg, South Africa.

Brown L and Amadon D, 1986. Eagles, Hawks and Falcons of the World. ISBN 978-1555214722.

Chehébar C and Martín S, 1989. Guía para el reconocimientomicroscópico de lospelos de los mamíferos de la Patagonia. Acta Vertebrata 16: 247-291.

Cornally A and Lawton C, 2016. A guide to the identification of Irish mammal hair. Irish Wildlife Manuals, No. 92. National parks and wildlife Service, Department of Arts, Heritage, Regional, Rural and Gaeltacht Affairs, Ireland.

Cortés-Avizanda A, 2010. Efectosecológicos de la heterogeneidadespacial y predecibilidaden la distribución de losrecursos: carroñas y gremios de carroñeros. Madrid, Spain: Universidad Autónoma de Madrid.

Donázar JA and Ceballos O, 1988. Alimentación y tasasreproductorasdelalimoche (Neophron percnopterus) en Navarra. Ardeola 35: 3-14.

Faliu L, Lignereux Y and Barrat J, 1980. Identification des poils des mammiferespyreneens. Donana, Acta Vertebrata 7: 125212.

Golawski A, Kasprzykowski Z and Said Al Sariri T, 2020. Foraging behaviour and diet in two sympatric shrike species during autumn migration across the Arabian Peninsula. Saudi Journal of Biological Sciences 27: 1462-1466. https://doi.org/10.1016/j.sjbs.2020.04.019

González LM, Margalida A, Sánchez R and Oria J, 2006. Supplementary feeding as an effective tool for improving breeding success in the Spanish Imperial Eagle (Aquila adalberti). Biological Conservation 129: 477-486. https://doi.org/10.1016/j.biocon.2005.11.014

Gutiérrez G, 1998. Estrategias de forrajeo. Pp. 359-381 in R. Ardila, W. López, A. M. Pérez, R. Quiñones and F Reyes, eds. Manual de análisis experimental del comportamiento. Madrid, Spain: Librería Nueva.

Hayward MW, Hofmeyr M, O'Brien J and Kerley GIH, 2006. Prey preferences of the Cheetah Acinonyx jubatus: morphological limitations or the need to capture rapidlyconsumable prey before kleptoparasites arrive? Journal of Zoology 270: 615-627. https://doi.org/10.1111/ j.1469-7998.2006.00184.x

Hiraldo F, Blanco JC and Bustamante J, 1991. Unspecialized exploitation of small carcasses by birds. Bird Study 38: 200207. https://doi.org/10.1080/00063659109477089

Hiraldo F, Delibes M and Calderón J, 1979. El Quebrantahuesos Gypaetus barbatus (L.). Monografías 22. Madrid:Instituto para la Conservación de la Naturaleza.
Houston DC, 1988. Competition for food between Neotropical vultures in forest. Ibis 130: 402-417. https://doi.org/ 10.1111/j.1474-919X.1988.tb08815.x

Jones GG, 2004. Conservation management of endangered birds. In: Sutherland WJ, Newton I \& Green RE (eds). Bird Ecology and Conservation: A Handbook of Techniques. Oxford University Press, Oxford, UK, pp: 269-301.

Kanaujia A and Kushwaha S, 2013. Vulnerable Vultures of India: Population, Ecology and Conservation. In: Rare Animals of India, Bentham Science Publishers, UAE 113-144. https://doi.org/10.2174/9781608054855113010009

Kanaujia A, Yadav R and Kumar A, 2019. Feeding behaviour and dietary preferences of vultures. Uttar Pradesh State Biodiversity Board. https://www.researchgate.net/ publication $/ 331988332$

Kendall COK, Virani MZ, Kirui P, Thomsett S and Githiru M, 2012. Mechanisms of Coexistence in Vultures: Understanding the Patterns of Vulture Abundance at Carcasses in Masai Mara National Reserve, Kenya. The Condor 114: 523-531. https://doi.org/10.1525/cond.2012. 100196

Kichloo MA, Kumar S and Sharma N, 2020. Breeding site records of three sympatric vultures in a mountainous cliff in Kahara Thathri, Jammu and Kashmir, India. Journal of Threatened Taxa, 12 9: 16166-16169. https://doi.org/10.11609/ jott.5537.12.9.16166-16169

Kruuk H, 1967. Competition for food between vultures in East Africa. Ardea 55: 171-193.

Li DL and Kasorndorkbua C, 2008. The status of the Himalayan Griffon Gyps himalayensis in South-East Asia. Forktail 24: 57-62.

Litvaitis JA, 2000. Investigating food habits of terrestrial vertebrates. In Boitani L, Fuller TK eds, Research techniques in Animal Ecology. Controversies and Consequences. Columbia university press, New York, USA, pp: 165-190.

Lu X, Ke D, Zeng X, Gong G and Ci R, 2009. Status, ecology and conservation of the Himalayan Griffon Gyps himalayensis (Aves, Accipitridae) in the Tibetan plateau. Ambio 38: 166173. https://doi.org/10.1579/0044-7447-38.3.166

Magurran AE, 1988. La Diversidad Ecológica y sumedición. Ed. Vedrá Barcelona.

Margalida A, 2008. Presence of bone remains in the ossuaries of Bearded Vultures Gypaetus barbatus: storage or nutritive rejection? Auk 125: 560-564. https://doi.org/10.1525/ auk.2008.07124

Margalida A, 2008. Bearded Vultures (Gypaetus barbatus) prefer fatty bones. Behavioural Ecology and Sociobiology 63: 187193. https://doi.org/10.1007/s00265-008-0649-6

Margalida A, Bertran J and Heredia R, 2009. Diet and food preferences of the endangered Bearded vulture Gypaetus barbatus: a basis for their conservation. Ibis 151: 235-243. https://doi.org/10.1111/j.1474-919X.2008.00904.x

Moreno-Opo R, Trujillano A and Margalida A, 2016. Behavioural coexistence and feeding efficiency drive niche partitioning at carcasses within the guild of European avian scavengers. Behavioral Ecology 27: 1041-1052. https://doi.org/10.1093/ beheco/arw010

Orlowski G and Karg J, 2013. Partitioning the effects of livestock farming on the diet of an aerial insectivorous passerine, the Barn Swallow Hirundorustica. Bird study 60: 111-123. https://doi.org/10.1080/00063657.2012.748717

Pande S, Yosef R, Morelli F, Pawar R and Mone R, 2018. Diet and habitat affinities in six raptor species in India. Avian Research 9: 36. https://doi.org/10.1186/s40657-018-0129-2.

Pianka ER, 1973: The structure of lizard communities. Annual Review of Ecology and Systematics. Palo Alto 4: 53-74. https://doi.org/10.1146/annurev.es.04.110173.000413

Pianka ER, 1985. Ecologíaevolutiva. Barcelona, Spain: Omega. 
Pianka ER, 1974: Niche overlap and diffuse competition. Proceedings of the National Academy of Science USA 71: 2141-2145. https://doi.org/10.1073/pnas.71.5.2141

Pianka ER, 1975. Niche relations of desert lizards, p. 292-314. In: M. Cody \& J.M. Diamond (Eds). Ecology and evolution of communities. Cambridge, Harvard University Press, USA, pp: 560.

Rasmussen PC and Anderton JC, 2005. Birds of South Asia, The Ripley Guide. 2. Edicions Washington DC, USA, pp: 90-91.

Rather MA, 2016. Wildlife Mapping Project and Land Degradation. Department of Wildlife protection, Government of Jammu and Kashmir.

Reynolds R and Meslow E, 1984. Partitioning of food and niche characteristics of coexisting accipiter during breeding. The Auk: Ornithological Advances 101: 761-779. https://doi.org/ 10.2307/4086903

Sabo SR, 1980. Niche and habitat relations in subalpine bird communities of the White Mountains of New Hampshire. Ecological Monographs 50: 241-259. https://doi.org/ $10.2307 / 1942481$

Sarà $M$ and Di Vittorio $M, 2003$. Factors influencing the distribution, abundance and nest-site selection of an endangered Egyptian vulture (Neophron percnopterus) population in Sicily. Animal Conservation Forum 6: 317328. https://doi.org/10.1017/S1367943003003391

Schmutz JK, Schmutz SM and Boag DA, 1980. Coexistence of three species of hawks (Buteo spp.) in the prairie-parkland ecotone. Canadian Journal of Zoology 58: 1075-1089. https://doi.org/10.1139/z80-151

Sonerud GA, Hansen H and Smedshaug CA, 2002. Individual roosting strategies in a flock-living bird: movement and social cohesion of hooded crows (corvus coronecornix) from pre roost gatherings to roost sites. Behavioral Ecology and Sociobiology 51: 309-318. https://doi.org/10.1007/s00265$\underline{001-0440-4}$
Stolen ED, 1996. Black and turkey vulture interactions with bald eagles in florida. Florida Field Naturalist 24: 43-45.

Taher MM, Al-Dubakel AY and Al-Lamy JH, 2016. Trophic breadth and dietary overlap for ten fish species caught from Shatt Al-Arab River, Fao, southern Iraq. Al-Kufa University Journal for Biology 8: 100-108.

Teerink BJ, 1991. Hair of West-European Mammals. Atlas and Identification Key. Cambridge University Press, Cambridge.

Virani M, Giri JB, Watson R and Baral HS, 2008. Surveys of Himalayan vultures (Gyps himalayensis) in the Annapurna Conservation Area, Mustang, Nepal. Journal of Raptor Research 42: 197-203. https://doi.org/10.3356/JRR-07-35.1

Wani HM, Bhat BA, Fazili MF, Shansaz UH, Haq IU and Bhat RA, 2018. Status of vultures in India: A review. International Journal of Advanced Scientific Research and Management 3: 181-187.

Wani HM, Fazili MF and Charoo SA, 2020. Status of Lammergeier (Gypaetus barbatus) in Hirpora Wildlife Sanctuary, South Kashmir. ELA Journal of Forestry and Wildlife 9: 772-775.

Wani HM, Fazili MF, Charoo SA, Bhat BA and Bhat RA, 2020. Evaluating population, threats and peoples attitude in relation to Himalayan vulture (Gyps himalayensis) in Hirpora Wildlife Sanctuary, Kashmir: A call for conservation. Indian Forester 146: 932-937. https://doi.org/ 10.36808/if/2020/v146i10/153858

Wilson EE and Wolkovich EM, 2011. Scavenging: how carnivores and carrion structure communities. Trends in Ecology and Evolution 26: 129-135. https://doi.org/ 10.1016/j.tree.2010.12.011

Zduniak P, Kuczyński L, 2003. Breeding biology of the hooded crow corvus coronecornix in Warta River Valley (W Poland). Acta Ornithologica 38: 143-150. https://doi.org/ $\underline{10.3161 / 068.038 .0201}$ 